\title{
Sodium nitroprusside activates potassium channels in the vena cava in normotensive but not in hypertensive rats
}

\begin{abstract}
Michele Paulo ${ }^{1}$, Alice Valença Araujo ${ }^{2}$ and Lusiane Maria Bendhack ${ }^{1}$
Despite the importance of the venous system in the regulation of blood pressure, there are few studies that evaluate venous function in health and disease, and the effects of drugs on venous function. Blood pressure depends directly on the peripheral resistance and cardiac output. Unlike the peripheral resistance, in which the contractile activity of the arteries is the key factor, cardiac output depends primarily on the venomotor tone. An increase in cardiac blood pressure can be caused by an increase in blood volume, structural changes in the walls of the veins, leading to a reduced compliance thereof, or an increase in the contractile activity of venous smooth muscle. This study examined the effect of sodium nitroprusside (SNP), a classical nitric oxide donor, on vascular relaxation in the vena cava from normotensive $(2 \mathrm{~K})$ and renal hypertensive (2K-1C) rats. We studied the effect of this compound in vena cava rings from normotensive and renal hypertensive rats. We showed for the first time that the vascular relaxation induced by SNP is impaired in vena cavas from hypertensive rats because of an impaired functional activity of potassium channels. Another relevant finding of this study is that the sarcoplasmic reticulum $\mathrm{Ca}^{2}+\mathrm{ATPase}$ is not involved in the venorelaxation induced by SNP.
\end{abstract}

Hypertension Research (2013) 36, 765-769; doi:10.1038/hr.2013.49; published online 20 June 2013

Keywords: nitric oxide donor; renal hypertension; sodium nitroprusside; venorelaxation

\section{INTRODUCTION}

Nitric oxide (NO) donors are pharmacologically active substances that release NO in vivo or in vitro. The classical NO donors are nitroglycerin and sodium nitroprusside (SNP). They have an important therapeutic effect in the treatment of many cardiovascular diseases such as angina pectoris and hypertension. The major clinical benefit of NO donors is attributed to their venodilator effect, resulting in decreased venous return, cardiac preload, high blood pressure and decreased myocardial oxygen demand. ${ }^{1}$

Arterial pressure depends directly on the peripheral resistance and cardiac output. Unlike the peripheral resistance, in which the contractile activity of the arteries is the key factor, cardiac output depends mainly on the venomotor tone. An increase in cardiac blood pressure can be caused by an increase in blood volume, structural changes in the walls of the veins, leading to the reduced compliance thereof, or an increase in the contractile activity of venous smooth muscle. ${ }^{2}$

Veins are structurally and functionally different from arteries. Veins have a smaller smooth muscle layer compared with arteries, but being able to accommodate $70 \%$ of the circulating blood volume, veins can modulate cardiovascular homeostasis and contribute significantly to hypertension pathogenesis. ${ }^{3}$
On a quantitative basis, changes in venous capacitance have a major role in the control of venous return and cardiac output, because $60-75 \%$ of the total blood volume is contained in the veins. ${ }^{4}$ Greene and Shoukas, ${ }^{5}$ by the simultaneous determination of cardiac function and venous return curves in dogs, showed that a maximal reflex change in venous capacitance could alter the cardiac output by up to $40 \%$. Thus, changes in venous function have important implications for the control of cardiac output and cardiovascular homeostasis. ${ }^{6}$ Despite the importance of the venous system in the regulation of blood pressure and cardiac output, there are few studies that evaluate venous function in health and disease conditions, and the effects of drugs on venous function. The lack of research in this area is probably due to the technical difficulties associated with venous studies. ${ }^{7}$ Therefore, we hypothesized that the NO donor, SNP, is able to induce vascular relaxation in vena cava rings from normotensive and renal hypertensive $2 \mathrm{~K}-1 \mathrm{C}$ rats.

Despite the importance of the veins in blood pressure control and in coronary vasodilation, there are few studies showing the effect of NO donors on this system. The present study aimed to investigate the vasodilator effect of SNP and the cellular mechanisms activated by

${ }^{1}$ Department of Physics and Chemistry, Laboratory of Pharmacology, Faculty of Pharmaceutical Sciences of Ribeirão Preto-University of São Paulo, Ribeirão Preto, Brazil and 2School of Medicine of Ribeirão Preto, University of São Paulo-USP, Ribeirão Preto, Brazil

Correspondence: Dr M Paulo, Laboratório de Farmacologia, Faculdade de Ciências Farmacêuticas de Ribeirão Preto—USP, Av. do Café s/nº Bloco S, 14040-903 Ribeirão Preto, Brazil. 
NO release from this NO donor in vena cavas from renal hypertensive rats compared with normotensive rats.

\section{METHODS}

\section{Animals}

This study was approved by the Ethics Committee of the University of São Paulo (08.1.432.53.8). Male rats $(180-200 \mathrm{~g})$ were used in the present study. Renovascular hypertension $(2 \mathrm{~K}-1 \mathrm{C})$ was produced by placing a silver clip $(0.2 \mathrm{~mm}$ internal diameter) on the left renal artery while rats were under anesthesia with tribromoethanol $\left(25 \mathrm{mg} \mathrm{kg}^{-1}\right.$, administered i.p.). Control rats (2K) were only subjected to laparotomy. This technique was described by Goldblatt et al. ${ }^{8}$ and adapted by Shaffemburg ${ }^{9}$ for small animals. Rats were maintained on standard chow, and the systolic blood pressure was measured using the tail-cuff method at 6 weeks after surgery. Rats were considered to be hypertensive when the systolic blood pressure was $>160 \mathrm{~mm} \mathrm{Hg}$.

\section{Drugs}

All drugs were purchased from Sigma (St Louis, MO, USA).

\section{Functional studies}

Preparation of vena cava rings. The inferior vena cava was isolated, cut into rings and mounted between two steel hooks to measure the isometric tension, which was recorded on a polygraph (Letica Scientific Instruments, Barcelona, Spain). The rings were placed in organ chambers containing Krebs' solution of the following composition (in mmoll ${ }^{-1}$ ): $\mathrm{NaCl} 130 ; \mathrm{KCl} 4.7 ; \mathrm{KH}_{2} \mathrm{PO}_{4} 1.2$; $\mathrm{MgSO}_{4}$ 1.2; $\mathrm{NaHCO}_{3}$ 14.9; glucose 5.5 and $\mathrm{CaCl}_{2}$ 1.6. The solution was maintained at $\mathrm{pH} 7.4$ and gassed with $95 \% \mathrm{O}_{2}$ and $5 \% \mathrm{CO}_{2}$ at $37^{\circ} \mathrm{C}$. The rings were initially stretched to a basal tension of $0.5 \mathrm{~g}$, before being allowed to equilibrate for $60 \mathrm{~min}$ in the bath fluid, which was changed every $20 \mathrm{~min}$. To verify the viability of the rings, they were stimulated twice with $10 \mathrm{mmoll}^{-1}$ 5-hydroxytryptamine hydrochloride. The preparations were considered viable when the contractile responses presented similar amplitudes. The tissues were washed, and to avoid interference from endogenous NO while assaying the effect of the NO donor, preparations with intact endothelium were preincubated with $0.1 \mathrm{mmoll}^{-1}$ L-nitro-L-arginine methyl ester, a non-selective NOS inhibitor, for $30 \mathrm{~min}$ prior to all the protocols performed on the vena cava rings. The tissues were pre-contracted with the contractile agent endothelin-1 at the half-maximal contraction $\left(\mathrm{EC}_{50}\right)$ concentration $\left(3 \mathrm{nmoll}^{-1}\right)$, and specific protocols were performed on vena cava rings isolated from $2 \mathrm{~K}-1 \mathrm{C}$ and $2 \mathrm{~K}$ rats.

\section{Experimental protocols}

Concentration-effect curves for SNP. Vena cava rings were contracted with endothelin-1 $\left(3 \mathrm{nmoll}^{-1}\right)$. When the contraction in response to endothelin-1 had reached a plateau, SNP $\left(0.1 \mathrm{nmol} 1^{-1}-1 \mu \mathrm{moll}^{-1}\right)$ was added cumulatively.

The effect of oxyhemoglobin, 4,5-dihydroxybenzene-1,3-disulfonate (tiron), $1 \mathrm{H}$ [1,2,4]oxadiazolo[4,3-alpha]quinoxalin-1-one, Rp-8-Br-PET-cyclic GMPS, sodium salt (Rp-8-Br-PET-GMPc), thapsigargin and $\mathrm{K}^{+}$channel blockers on the relaxation response to SNP. To test the effects of other compounds on the response of the vena cava to SNP, the following compounds were applied to the vena cava rings at the indicated concentrations $30 \mathrm{~min}$ before adding endothelin-1 $\left(3 \mathrm{nmoll}^{-1}\right)$ : sodium 4,5-dihydroxybenzene-1,3-disulfonate (tiron), a free radical scavenger $\left(100 \mu \mathrm{moll}^{-1}\right) ; 1 \mathrm{H}-[1,2,4]$ oxadiazolo[ $[4,3-$ alpha]quinoxalin-1-one (ODQ), a soluble guanylyl-cyclase inhibitor $\left(1 \mu \mathrm{moll}^{-1}\right)$; Rp-8-Br-PET-cyclic GMPS sodium salt (Rp-8-Br-PET-GMPc), a competitive inhibitor of protein kinase $\mathrm{G}\left(3 \mu \mathrm{moll}^{-1}\right)$; thapsigargin, a potent sarcoplasmic reticulum $\mathrm{Ca}^{2+}$-ATPase (SERCA) inhibitor $\left(1 \mu \mathrm{moll}^{-1}\right)$; tetraethylammonium (TEA), a non-selective $\mathrm{K}^{+}$channel blocker $\left(1 \mathrm{mmoll}^{-1}\right)$; glibenclamide, an ATP-sensitive $\mathrm{K}^{+}$channel channel blocker $\left(3 \mu \mathrm{moll}^{-1}\right)$; 4 -aminopiridine, a voltage-dependent $\mathrm{K}^{+}$channel blocker $\left(1 \mathrm{mmoll}{ }^{-1}\right)$; apamin, a small conductance $\mathrm{Ca}^{2+}$-dependent $\mathrm{K}^{+}$channel blocker $\left(1 \mathrm{moll}^{-1}\right)$; paxilline, a large conductance $\mathrm{Ca}^{2+}$-dependent $\mathrm{K}^{+}$channel blocker $\left(1 \mu \mathrm{mol} 1^{-1}\right)$ and barium chloride, an inwardly rectifying $\mathrm{K}^{+}$channel blocker $\left(30 \mu \mathrm{moll}^{-1}\right)$. Subsequently, cumulative SNP concentration-response curves were constructed. The effect of the duration of incubation of the tissue with the various inhibitors was investigated and found to have no effect on the baseline.

\section{Data analysis}

Data are expressed as the mean \pm s.e.m. with $n$ indicating the number of animals. The maximum effect was considered as the maximal amplitude response reached in the concentration-effect curves for each relaxant agent. The concentration of the agent producing a half-maximal relaxation amplitude $\left(\mathrm{EC}_{50}\right)$ was determined after logarithmic transformation of the normalized concentration-response curves, and $\mathrm{EC}_{50}$ values are reported as the negative logarithm $\left(\mathrm{pD}_{2}\right)$ of the mean of the individual values for each tissue. Statistical

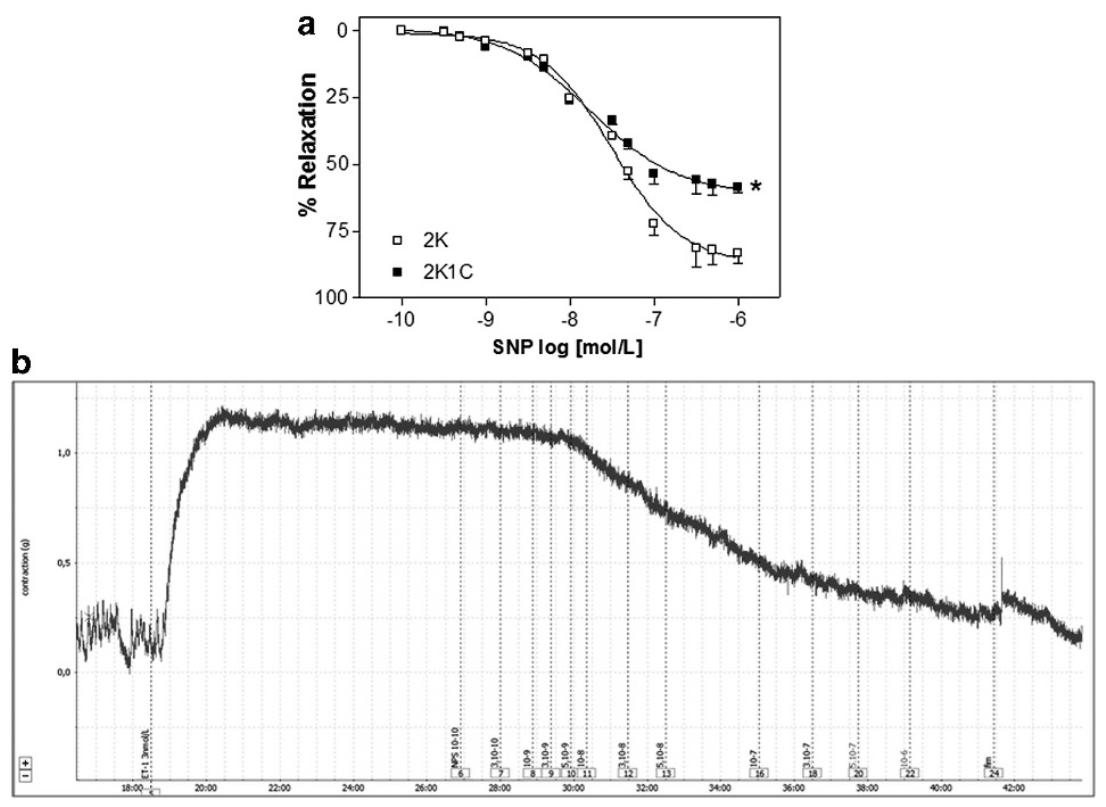

Figure 1 (a) Effects of sodium nitroprusside (SNP) on the vena cava from normotensive ( $\square 2 \mathrm{~K}$ ) and hypertensive rats ( $\mathbf{\square} 2 \mathrm{~K}$-1C) pre-contracted with endothelin-1 $\left(E T-1,3 \mathrm{nmolI}^{-1}\right)$. Data are expressed as mean \pm s.e.m. Experiments were performed on preparations obtained from seven different animals. *denotes a significant difference $(P<0.05)$ compared with the normotensive rat. (b) Representative tracing of the force in rat vein rings. A full color version of this figure is available at the Hypertension Research journal online. 
analysis was performed using the $t$-test or two-way analysis of variance (ANOVA) with the Bonferroni post test. $P<0.05$ was considered significant.

\section{RESULTS}

Systolic blood pressure was significantly higher in $2 \mathrm{~K}-1 \mathrm{C}$ rats $(210 \pm 7 \mathrm{~mm} \mathrm{Hg}, n=30)$ than in $2 \mathrm{~K}$ rats $(112 \pm 2 \mathrm{~mm} \mathrm{Hg}, n=30)$ 6 weeks after surgery.

SNP-induced relaxation in the vena cava rings from $2 \mathrm{~K}$ and $2 \mathrm{~K}-1 \mathrm{C}$ rats in a concentration-dependent way, as shown in Figure 1a. The maximum effect values (2K-1C: $58.6 \pm 3.3 \%, 2 \mathrm{~K}: 83.3 \pm 2.4 \%$; $P<0.05$ ), but not the $\mathrm{pD}_{2}$ values, obtained from $2 \mathrm{~K}-1 \mathrm{C}$ rats were lower in vena cava rings compared with those obtained from $2 \mathrm{~K}$ rats. Figure $1 \mathrm{~b}$ shows a tracing of force in rat vein rings.

As shown in Figure 2a, tiron increased the maximum effect in vena cava rings from $2 \mathrm{~K}$ rats (from $83.3 \pm 2.4$ to $97.9 \pm 3.8 \%, n=6$; $P<0.05$ ) and $2 \mathrm{~K}-1 \mathrm{C}$ rats (from $58.6 \pm 3.3$ to $75.8 \pm 3.7 \%, n=6$; $P<0.05)$. The relaxation induced by SNP was almost abolished by the guanylyl-cyclase inhibitor (ODQ) in vena cava rings from $2 \mathrm{~K}$ and $2 \mathrm{~K}-1 \mathrm{C}$ rat (Figure $2 \mathrm{~b}$ ).

As shown in Figure 3a, the inhibition of protein G kinase (GK) with Rp-8-Br-PET-cGMP reduced the maximum effect in $2 \mathrm{~K}$ rat vena cava (from $83.3 \pm 2.4$ to $42.7 \pm 2.8 \%, n=6 ; P<0.001$ ) and in $2 \mathrm{~K}-1 \mathrm{C}$ rat vena cava (from $58.6 \pm 3.3$ to $35.7 \pm 1.7 \%, n=6 ; P<0.001$ ).

The SERCA inhibitor thapsigargin had no effect on the relaxation induced by SNP in vena cava rings from $2 \mathrm{~K}$ and $2 \mathrm{~K}-1 \mathrm{C}$ rats (Figure $3 \mathrm{~b}$ ).

In vena cava rings from $2 \mathrm{~K}-1 \mathrm{C}$ rats, the relaxation induced by $\mathrm{SNP}$ was not inhibited by TEA, apamin, 4-aminopiridine, glibenclamide, paxilline or barium chloride (Table 1). The relaxation of vena cava rings from $2 \mathrm{~K}$ rats in the presence of selective $\mathrm{K}^{+}$channel blockers was not different from the response observed in aortic rings from the control animals (Table 1). However, the non-selective $\mathrm{K}^{+}$channel blocker (TEA) reduced the relaxation induced by SNP in $2 \mathrm{~K}$ rats (from $83.3 \pm 2.4$ to $52.1 \pm 3.7 \%, n=6 ; P<0.05$ ) but not in $2 \mathrm{~K}-1 \mathrm{C}$ rats (Figure 4 ).

\section{DISCUSSION}

We showed for the first time that the vascular relaxation induced by SNP is impaired in the vena cava from renal hypertensive rats. In this model of hypertension, impaired $\mathrm{K}^{+}$channels may contribute to decreased vasodilatation in response to SNP in the veins.

Several other studies have also demonstrated a reduction in $\mathrm{NO}$-dependent vasodilator responses in hypertensive rats in other vascular beds. Callera et al. ${ }^{10}$ and Bonaventura et al. ${ }^{11}$ reported a reduction in endothelium-dependent and independent relaxation in response to acetylcholine and SNP, respectively, in aortas isolated from $2 \mathrm{~K}-1 \mathrm{C}$ rats. This impairment has been attributed to the increased production of reactive oxygen species. ${ }^{12,13}$ Superoxide

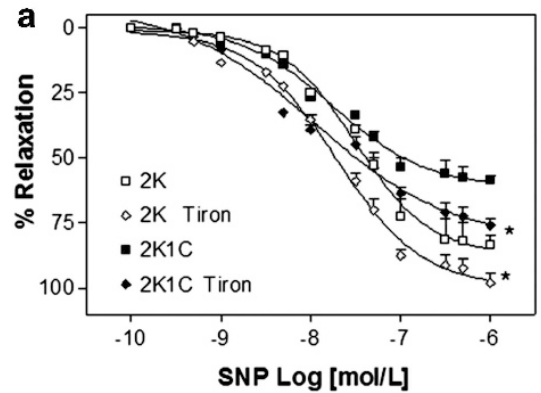

$\left(\mathrm{O}_{2}{ }^{-}\right)$is an important member of the reactive oxygen species family that has been found in elevated concentrations in the vascular smooth muscle cells from renal hypertensive rats. ${ }^{14} \mathrm{NO}$ bioavailability could be significantly reduced in the presence of $\mathrm{O}_{2}{ }^{-}$because $\mathrm{NO}$ reacts with $\mathrm{O}_{2}{ }^{-}$to form peroxynitrite $\left(\mathrm{ONOO}^{-}\right) .^{15}$

Therefore, we hypothesized that the vascular relaxation induced by SNP is impaired in the vena cava from $2 \mathrm{~K}-1 \mathrm{C}$ rats owing to the greater amount of $\mathrm{O}_{2}{ }^{-}$in this hypertension model. To confirm this hypothesis, we performed experiments using the $\mathrm{O}_{2}{ }^{-}$scavenger tiron. We found that tiron increased the maximum effect induced by SNP in the vena cava from both $2 \mathrm{~K}$ and $2 \mathrm{~K}-1 \mathrm{C}$ rats. These results suggest that reactive oxygen species such as $\mathrm{O}_{2}{ }^{-}$would be responsible for reduced bioavailability of $\mathrm{NO}$ in the vena cava from normotensive and hypertensive animals. However, it does not explain the lower vasodilator response to SNP in hypertensive animals found in the present study. Thus, this difference may be related to the deficiency in the mechanisms of vascular relaxation in hypertensive rats.

NO induces vascular smooth muscle relaxation mainly by activation of soluble guanylyl-cyclase enzyme (sGC) with consequent formation of cGMP and or by direct activation of $\mathrm{K}^{+}$channels. ${ }^{16}$ By using the selective inhibitor of sGC activity, ODQ, we found that this pathway is important for the venous relaxation triggered by SNP in normotensive and renal hypertensive rats. The cGMP accumulated after activation of sGC by $\mathrm{NO}$ can activate cGMP-dependent protein kinase, GGK. In our study, the inhibition of GK reduced the relaxation induced by SNP in the vena cava rings from $2 \mathrm{~K}$ and 2K-1C rats. Homer et al. ${ }^{17}$ also found differences in the effect of GK inhibition for different NO donors. In the rat pulmonary artery, the relaxation induced by spermine NONOate was minimally inhibited by the same inhibitor used in our study, whereas the relaxation induced by nitroglycerin was highly inhibited by Rp-8-Br-PET-cGMP.

We also investigated the involvement of SERCA in the relaxation mediated by SNP in the vena cava. In this vessel, SERCA does not seem to be involved. However, studies by Bonaventura et al. reported that the incubation of the aorta with another SERCA inhibitor, cyclopiazonic acid, affected the relaxation induced by SNP.

Membrane hyperpolarization is an important mechanism for the relaxation induced by nitrates in some vascular beds. ${ }^{18}$ It may occur due to the opening of $\mathrm{K}^{+}$channels in response to either $\mathrm{NO}^{16}$ or phosphorylation by protein kinases. ${ }^{19}$

The involvement of $\mathrm{K} \pm$ channels in relaxation induced by SNP could be better studied using the non-selective blocker of these channels, TEA. $^{20}$ In the present study, TEA reduced the relaxation induced by SNP only in the vena cava rings from $2 \mathrm{~K}$ rats. The main new finding of the present study is that the impaired relaxation of the vena cava from hypertensive rats is due to $\mathrm{K}^{+}$channel activation impairment.

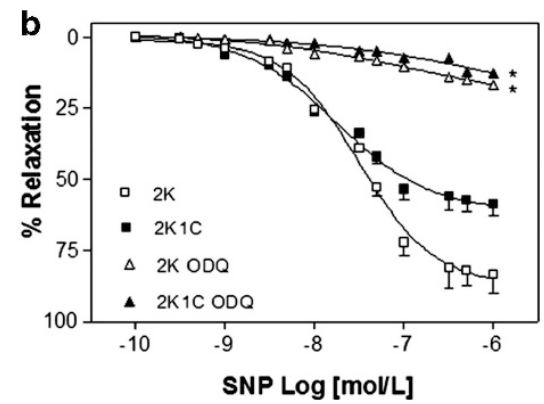

Figure 2 Effect of sodium 4,5-dihydroxybenzene-1,3-disulfonate (tiron), a free radical scavenger (a), and 1H-[1,2,4]oxadiazolo[4,3-alpha]quinoxalin-1-one $(\mathrm{ODQ})$, a soluble guanylate cyclase inhibitor (b), on the relaxation induced by sodium nitroprusside (SNP) in the vena cava from normotensive ( $\square 2 \mathrm{~K}$ ) and hypertensive $(\mathbf{2} \mathrm{K}-1 \mathrm{C})$ rats. Data are expressed as mean \pm s.e.m. of experiments performed on preparations obtained from seven different animals. *denotes a significant difference $(P<0.05)$ compared with the control. 

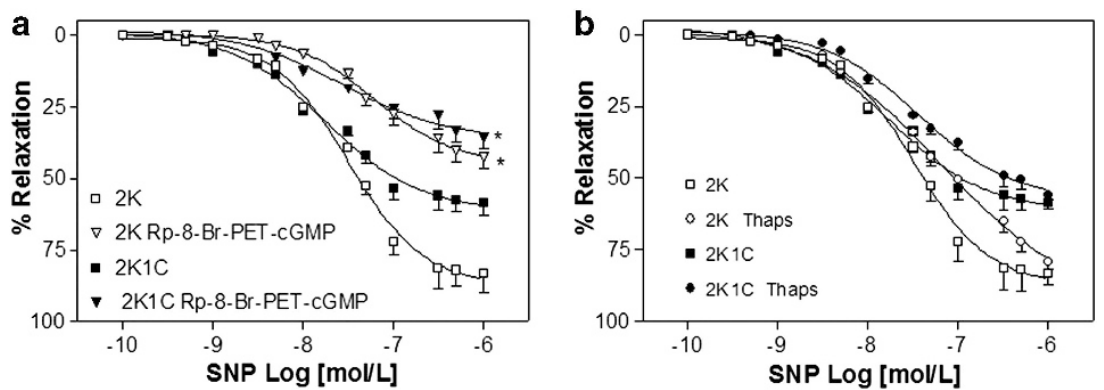

Figure 3 Effect of Rp-8-Br-PET-cyclic GMPS, sodium salt (Rp-8-Br-PET-GMPc), a competitive inhibitor of protein kinase G (a), and thapsigargin (Thaps), a potent sarcoplasmic reticulum $\mathrm{Ca}^{2}+$ ATPase (SERCA) inhibitor (b), on the relaxation induced by sodium nitroprusside (SNP) in vena cavas from normotensive $(\square 2 \mathrm{~K})$ and hypertensive $(\square 2 \mathrm{~K}-1 \mathrm{C})$ rats pre-contracted with endothelin-1 (ET-1; $3 \mathrm{nmol} \mathrm{I}^{-1}$ ). Data are expressed as mean \pm s.e.m. of $n$ experiments performed on preparations obtained from eight different animals. * denotes a significant difference $(P<0.05)$ compared with the control.

Table1 Effect of $\mathrm{K}^{+}$channel blockers on ME and $\mathrm{pD}_{2}$ values of SNP in vena cava rings from two kidney normotensive and two kidney, one clip hypertensive rats

\begin{tabular}{|c|c|c|c|c|}
\hline & \multicolumn{4}{|c|}{$S N P$} \\
\hline & \multicolumn{2}{|c|}{$2 K$} & \multicolumn{2}{|c|}{$2 K-1 C$} \\
\hline & $M E$ & $p D_{2}$ & $M E$ & $p D_{2}$ \\
\hline Control & $83.3 \pm 2.4 \%$ & $7.53 \pm 0.35$ & $58.7 \pm 3.3 \%$ & $7.34 \pm 0.26$ \\
\hline TEA & $52.1 \pm 3.7 \% *$ & $6.74 \pm 0.34$ & $48.2 \pm 1.6 \%$ & $7.35 \pm 0.55$ \\
\hline Gli & $76.5 \pm 4.7 \%$ & $7.44 \pm 0.31$ & $54.5 \pm 4.7 \%$ & $7.30 \pm 0.18$ \\
\hline 4-Ap & $77.5 \pm 3.7 \%$ & $7.45 \pm 0.35$ & $53.5 \pm 3.6 \%$ & $7.27 \pm 0.57$ \\
\hline Apa & $75.2 \pm 4.7 \%$ & $7.39 \pm 0.24$ & $55.2 \pm 4.6 \%$ & $7.28 \pm 0.33$ \\
\hline $\mathrm{BaCl}_{2}$ & $80.0 \pm 3.3 \%$ & $7.55 \pm 0.31$ & $59.3 \pm 3.5 \%$ & $7.39 \pm 0.49$ \\
\hline Pax & $78.2 \pm 2.7 \%$ & $7.49 \pm 0.26$ & $54.2 \pm 4.1 \%$ & $7.32 \pm 0.40$ \\
\hline
\end{tabular}

Abbreviations: 4-AP, 4-aminopiridine; Apa, apamin; $\mathrm{BaCl}_{2}$, barium chloride; Gli, glibenclamide; $\mathrm{ME}$, maximum effect; Pax, paxilline; SNP, sodium nitroprusside; TEA, tetraethylammonium. $* P<0.05$ vs, control.

The main types of $\mathrm{K}^{+}$channels are the $\mathrm{Ca}^{2+}$-activated $\mathrm{K}^{+}$ channels of high and low conductance $\left(\mathrm{SK}_{\mathrm{Ca}}\right.$ and $\left.\mathrm{BK}_{\mathrm{Ca}}\right)$, the inwardly rectifying $\mathrm{K}^{+}$channel, the voltage-dependent $\mathrm{K}^{+}$channel and the ATP-sensitive $\mathrm{K}^{+}$channel. In the present study, we used selective $\mathrm{K}^{+}$ channel blockers to identify which $\mathrm{K}^{+}$channel is involved in this response. To our surprise, our results showed that none of these blockers alone changed the relaxation induced by SNP in the vena cavas of normotensive or hypertensive rats. Hempelmann et al. ${ }^{21}$ have also investigated the contribution of $\mathrm{K}^{+}$channels to the relaxation induced by the NO donor, DEA-NONOate (DEA/NO), by using TEA, glibenclamide and 4-aminopyridine at the same concentrations that were used in this work. They showed that none of these blockers alone changed the relaxation stimulated with $\mathrm{DEA} / \mathrm{NO}$ in the basilar artery of Sprague-Dawley rats. However, when the selective blockers glibenclamide and 4-aminopyridine were incubated in the same preparation, the maximum effect induced by DEA/NO was decreased. ${ }^{21}$

They have hypothesized that when one subtype of $\mathrm{K}^{+}$channel is blocked, the others may overcome this blockade and the relaxation remains unaltered. However, when more than one subtype is blocked, the response is impaired. In fact, in our study, when we used the nonselective $\mathrm{K}^{+}$channel blocker that would block most of the $\mathrm{K}^{+}$ channels, the SNP-induced relaxation was impaired.

Taken together, our results show that SNP is able to induce the relaxation of the vena cava of the rat by activation of the cGMP/sGC/ GK pathway and potassium channels, and this process does not

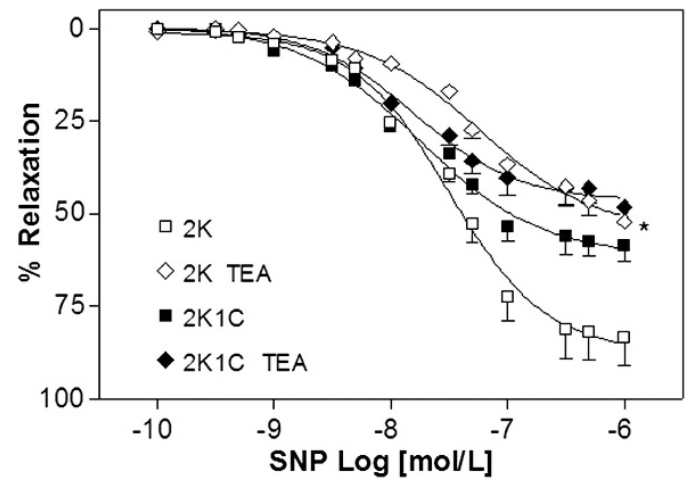

Figure 4 Effect of tetraethylammonium bromide (TEA), a potassium channel blocker, on the relaxation induced by sodium nitroprusside (SNP) in vena cava rings from normotensive $(\square 2 \mathrm{~K}$ ) and hypertensive ( $2 \mathrm{~K}-1 \mathrm{C}$ ) rats. Data are expressed as mean \pm s.e.m. of $n$ experiments performed on preparations obtained from eight different animals. * denotes a significant difference $(P<0.05)$ compared with the control.

involve SERCA. However, SNP-induced relaxation is impaired in vena cavas from hypertensive rats, most probably due to the impairment of potassium channels.

\section{CONFLICT OF INTEREST}

The authors declare no conflict of interest.

\section{ACKNOWLEDGEMENTS}

We thank Juliana A Vercesi and Marcella D Grando for their excellent technical assistance. This work was supported by grants from Fundação de Amparo à Pesquisa do Estado de São Paulo (FAPESP) and Conselho Nacional de Desenvolvimento Científico e Tecnológico (CNPq).

1 MacPharson JD, Gillespie TD, Dunkerley HA, Maurice DH, Bennet BM. Inhibition of phosphodiesterase 5 selectively reverses nitrate tolerance in the venous circulation. $J$ Pharmacol Exp Ther 2006; 317: 188-195.

2 Fink GD, Johnson RJ, Galligan JJ. Mechanisms of increased venous smooth muscle tone in desoxycorticosterone acetate-salt hypertension. Hypertension 2000; 35 (Pt 2), 464-469.

3 Szasz T, Thakali K, Fink GD, Watts SW. A comparison of arteries and veins in oxidative stress: producers, destroyers, function, and disease. Exp Biol Med 2007; 232: 27-37.

4 Guyton A, Jones C, Coleman T. Circulatory Physiology: Cardiac Output and Its Regulation. WB Saunders, Philadelphia, PA, USA, 1973.

5 Greene AS, Shoukas AA. Changes in canine cardiac function and venous return curves by the carotid baroreflex. Am J Physiol 1986; 251: H288-H296.

6 Martin DS, Rodrigo MC, Appelt CW. Venous tone in the developmental stages of spontaneous hypertension. Hypertension 1998; 31: 139-144. 
7 Pang CC. Measurement of body venous tone. J Pharmacol Toxicol Methods 2000; 44: 341-360.

8 Goldblatt H, Lynch J, Hamzal RF, Summerville WW. Studies on experimental hypertension. The production of persistent elevation of systolic blood pressure by means of renal ischemia. J Exp Med 1934; 59: 347-379.

9 Shaffemburg CA. Device to control constriction of renal artery for production of hypertension in small animals. Proc Soc Biol Med 1959; 101: 676-677.

10 Callera GE, Varanda WA, Bendhack LM. $\mathrm{Ca}^{2+}$ influx increased in 2-kidney, 1-clip hypertensive rat aorta. Hypertension 2001; 38: 592-596.

11 Bonaventura D, de Lima RG, Vercesi JA, da Silva RS, Bendhack LM. Comparison of the mechanisms underlying the relaxation induced by two nitric oxide donors: sodium nitroprusside and a new ruthenium complex. Vasc Pharmacol 2007; 46: 215-222.

12 Keshari M, Thakali MS, Yanny Lau MS, Gregory D, James JG, Alex F, Watts SW. Mechanisms of hypertension induced by nitric oxide (NO) deficiency: focus on venous function. J Cardiovasc Pharmacol 2006; 47: 742-750.

13 Rodrigues GJ, Lunardi CN, Lima RG, Santos CX, Laurindo FR, Silva RS, Bendhack LM. Vitamin $C$ improves the effect of a new nitric oxide donor on the vascular smooth muscle from renal hypertensive rats. Nitric Oxide 2008; 18: 176-183.

14 Dhalla NS, Temsah RM, Netticadan T. Role of oxidative stress in cardiovascular diseases. J Hypertens 2000; 18: 655-673.
15 Hamilton CA, Brosnan MJ, McIntyre M, Graham D, Dominiczak AF. Superoxide excess in hypertension and aging. A common cause of endothelial dysfunction. Hypertension 2001; 37: 529-534.

16 Bolotina VM, Najibi S, Palacino H, Pagano PJ, Cohen RA. Nitric oxide directly activates calcium-dependent potassium channels in vascular smooth muscle cells. Nature 1994; 3: 850-853.

17 Homer KL, Fiore SA, Wanstall JC. Inhibition by $1 \mathrm{H}-[1,2,4]$ oxadiazolo[4,3-a]quinoxalin-1-one $(O D Q)$ of responses to nitric oxide-donors in rat pulmonary artery: influence of the mechanism of nitric oxide generation. J Pharm Pharmacol 1999; 51: 135-139.

18 Tare M, Parkington HC, Coleman HA, Neild TO, Dusting GJ. Hyperpolarization and relaxation of arterial smooth muscle caused by nitric oxide derived from the endothelium. Nature 1990; 346: 69-71.

19 Robertson BE, Schubert R, Hescheler J, Nelson MT. cGMP-dependent protein kinase activates $\mathrm{Ca}^{2+}$ activated potassium channels in cerebral artery smooth muscle cells. Am J Physiol 1993; 265: 229-303.

20 Demirel E, Rusko J, Laskey RE, Adams DJ, van Breemen C. TEA inhibits ACh-induced EDRF release: endothelial $\mathrm{Ca}^{(2+)}$-dependent $\mathrm{K}^{+}$channels contribute to vascular tone. Am J Physiol 1994; 267 (Pt 2), H1135-H1141.

21 Hempelmann R,G, Seebeck J, Kruse ML, Ziegler A, Mehdorn HM. Role of potassium channels in the relaxation induced by the nitric oxide (NO) donor DEA/NO in the isolated rat basilar artery. Neurosci Lett 2001; 313: 21-24. 